American Journal of Environmental Sciences 6 (1): 41-44, 2010

ISSN 1553-345X

(C) 2010 Science Publications

\title{
Removal of Cadmium, Copper, Lead and Nickel from Aqueous Solution by White, Yellow and Red United Arab Emirates Sand
}

\author{
L. Pappalardo, F. Jumean and N. Abdo \\ Department of Biology and Chemistry, American University of Sharjah, \\ P.O. Box 26666, Sharjah, United Arab Emirates
}

\begin{abstract}
Problem statement: To remove toxic heavy metal ions from wastewater using local sand as a low cost adsorbent. Approach: Removal efficiency of $\mathrm{Cd}(\mathrm{II}), \mathrm{Cu}(\mathrm{II}), \mathrm{Pb}(\mathrm{II})$ and $\mathrm{Ni}(\mathrm{II})$ from aqueous solution by white, yellow and red UAE sand was investigated at $25.0^{\circ} \mathrm{C}$ using the methods of batch equilibrium adsorption and column filtration. In each case, a mixture containing $20 \mathrm{ppm}$ of each ion was employed. In the equilibrium study, the effect of sand dosage was measured for mixtures containing $20 \mathrm{ppm}$ of each ion. In the column filtration study, the mixture was added to a column packed with yellow sand and the composition of the effluent was measured for each $0.050 \mathrm{dm}^{3}$ portion. Concentrations were measured on an inductively coupled plasma-atomic emission spectrometer "ICPAES". Results: Removal efficiency by sand type was found to follow the order yellow $>$ white $>$ red. At low sand dosages, removal efficiencies of $\mathrm{Pb}(\mathrm{II})$ and $\mathrm{Cu}(\mathrm{II})$ were much higher than those for $\mathrm{Ni}$ (II) and $\mathrm{Cd}(\mathrm{II})$. For example, at a sand dosage of $0.02 \mathrm{~kg} \mathrm{dm}^{-3}$, removal efficiencies of $\mathrm{Pb}(\mathrm{II}), \mathrm{Cu}(\mathrm{II}), \mathrm{Cd}(\mathrm{II})$ and $\mathrm{Ni}$ (II) were, respectively, 95, 86, 33 and 23\% for yellow sand; 89, 86, 30 and 18\% for white sand; and $75,63,12$ and $13 \%$ for red sand. Column filtration using yellow sand confirmed that removal efficiency followed the order $\mathrm{Pb}(\mathrm{II})>\mathrm{Cu}(\mathrm{II})>\mathrm{Cd}(\mathrm{II})>\mathrm{Ni}(\mathrm{II})$, with all four ions completely removed at mass ratios (metal/sand) lower than $3.0 \times 10^{-4}$. Conclusion: Equilibration on sand and sand filtration are most efficient for the removal $\mathrm{Pb}$ (II) and $\mathrm{Cu}$ (II). Sand filtration can be effectively utilized to separate $\mathrm{Pb}(\mathrm{II})$ and $\mathrm{Cu}(\mathrm{II})$ from a mixture containing all four ions.
\end{abstract}

Key words: UAE sand, heavy metal removal, cadmium, copper, lead, nickel

\section{INTRODUCTION}

Many industrial processes such as electroplating, galvanization, dyeing and tanning, release heavy metals into the environment. Heavy metals in industrial wastewater are particularly hazardous and are often detrimental to health. The search for low cost methods to remove them is thus of particular significance.

In a previous communication from this laboratory (Khamis et al., 2009), we reported on the removal and speciation of $\mathrm{Cr}(\mathrm{III})$ and $\mathrm{Cr}(\mathrm{VI})$ from wastewater using white, red and yellow United Arab Emirates (UAE) sand. The positive outcome of that study has prompted us to extend this study to other heavy metals. This study deals with the removal of $\mathrm{Cd}(\mathrm{II}), \mathrm{Cu}$ (II), $\mathrm{Pb}$ (II) and $\mathrm{Ni}(\mathrm{II})$ from a mixture by batch equilibration with sand and by sand column filtration.

Some of the methods cited in the literature for removal of heavy metals include precipitation, ion exchange, adsorption, solvent extraction and biosorption. Recently, adsorption studies were conducted using low cost adsorbents such as wool (Balkaya, 2002), sawdust (Dakiky et al., 2002), cocoa shell (Meunier et al., 2003) and zeolite (Babel and Kumiawan, 2004). Several reports deal with the use of sand as an inexpensive and efficient adsorbent of heavy metal from industrial effluents (Aslam et al., 2004; Baig et al., 2003; Muhammad et al., 1998; Awan et al., 2003) but there is only a single report (Khamis et al., 2009) on the effect of sand type on the extent of heavy metal removal. This study aims at comparing the efficiency of the various types of UAE sand in removing cadmium, copper, lead and nickel from industrial wastewater, using equilibrium and dynamic methods.

\section{MATERIALS AND METHODS}

All primary chemicals used were of analytical reagent grade. $\mathrm{Cu}\left(\mathrm{NO}_{3}\right)_{2}$ was purchased from Riedel De-Haen (Germany). $\mathrm{CdCl}_{2}$ was purchased from $\mathrm{BDH}$ (UK). $\mathrm{Pb}\left(\mathrm{NO}_{3}\right)_{2}, \mathrm{Ni}\left(\mathrm{NO}_{3}\right)_{2}, \mathrm{NaOH}$ and $\mathrm{HNO}_{3}$ were purchased from Panreac (Spain). White, yellow and red

Corresponding Author: F. Jumean, Department of Biology and Chemistry, American University of Sharjah, P.O. Box 26666, Sharjah, United Arab Emirates Tel: + 971-5152407 Fax: + 971-5152450 
sand grab samples were obtained from several locations within the UAE and randomized.

Metal ion concentrations were determined using a Varian Liberty axial sequential inductively coupled plasma-atomic emission spectrometer "ICP-AES" (Australia). pH was measured on a 550A Thermo Orion $\mathrm{pH}$ meter (USA) fitted with a combined glass electrode. Solutions were shaken at $25.0 \pm 0.1^{\circ} \mathrm{C}$ using an Edmund Buhler KS-15/TH-15 shaker (Germany). Sand samples were sieved using impact test sieves from Standard Sieve (USA), mesh model BS410, 1986 ST. Three stainless steel frames with sieve sizes 300, 150 and $75 \mu \mathrm{m}$. The selected fractions used in experiments were less than $300 \mu \mathrm{m}$ in diameter. Each sand sample was washed repeatedly with deionized distilled water and dried to a constant weight at $110^{\circ} \mathrm{C}$.

For equilibration experiments stock solutions containing 1000 ppm of $\mathrm{Cd}(\mathrm{II}), \mathrm{Cu}(\mathrm{II}), \mathrm{Pb}(\mathrm{II})$ and $\mathrm{Ni}(\mathrm{II})$ were prepared. These were then used to prepare mixtures containing $20 \mathrm{ppm}$ of each ion. The $\mathrm{pH}$ of all mixtures was adjusted to 4.0 using $50 \% \quad \mathrm{HNO}_{3}$. Experiments were conducted using a batch reaction process in triplicates. A known mass of sand was added to $0.100 \mathrm{dm}^{3}$ of the mixture in a $0.250 \mathrm{dm}^{3}$ flask and shaken at $25.0^{\circ} \mathrm{C}$ for $2 \mathrm{~h}$ at $200 \mathrm{rpm}$. Ion concentrations were determined using ICP. Data were collected for sand dosages in the range $0-0.180 \mathrm{~kg}$ sand $\mathrm{dm}^{-3}$ solution. Prolonging the contact time between sand and solution beyond $2 \mathrm{~h}$ did not result in additional removal of heavy metal ions, from which it was concluded that $2 \mathrm{~h}$ was sufficient to attain equilibrium.

Removal of the four heavy metal ions was also investigated using a dynamic approach. A column, $0.225 \mathrm{~m}$ in height and $0.025 \mathrm{~m}$ in diameter, was packed with yellow sand to a height in the range 0.050$0.100 \mathrm{~m}$. Yellow sand was selected because equilibration data showed that it had the highest heavy metal removal efficiency. Prior to each run, the column was washed with $1.5 \mathrm{dm}^{3}$ of distilled deionized water. $9.0 \mathrm{dm}^{3}$ of the heavy metal mixture, containing $20 \mathrm{ppm}$ of each ion, was added to the column and the flow rate adjusted in the range $0.3-0.6 \mathrm{dm}^{3} \mathrm{~h}^{-1}$. Concentrations of heavy metals in the effluent were measured at $0.050 \mathrm{dm}^{3}$ intervals.

The removal efficiency is defined as follows:

Removal efficiency $=\left[\frac{C_{I}-C_{F}}{C_{I}}\right] \times 100$

where, $\mathrm{C}_{\mathrm{I}}$ and $\mathrm{C}_{\mathrm{F}}$ are the initial concentration and the concentration after treatment.

\section{RESULTS}

Batch equilibration: Heavy metal ion removal efficiencies from mixtures containing $20 \mathrm{ppm}$ $\mathrm{Cd}(\mathrm{II}), \mathrm{Cu}(\mathrm{II}), \mathrm{Pb}(\mathrm{II})$ and $\mathrm{Ni}(\mathrm{II})$, after equilibration on sand, are shown in Fig. 1. These efficiencies are plotted as a function of sand type and dosage.

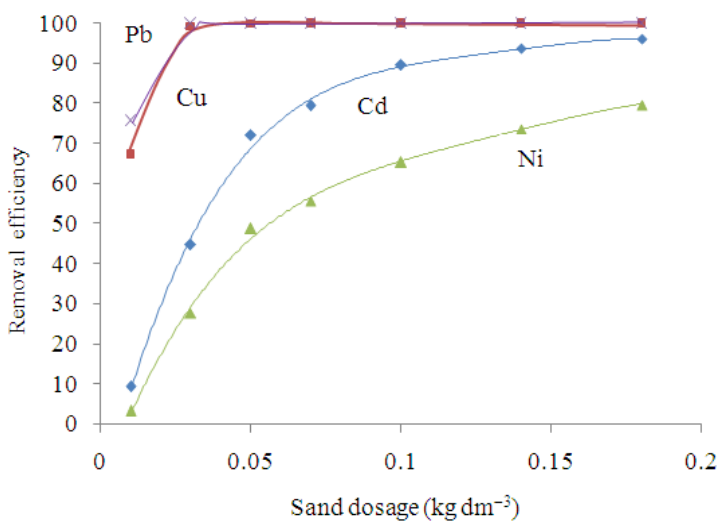

(a)

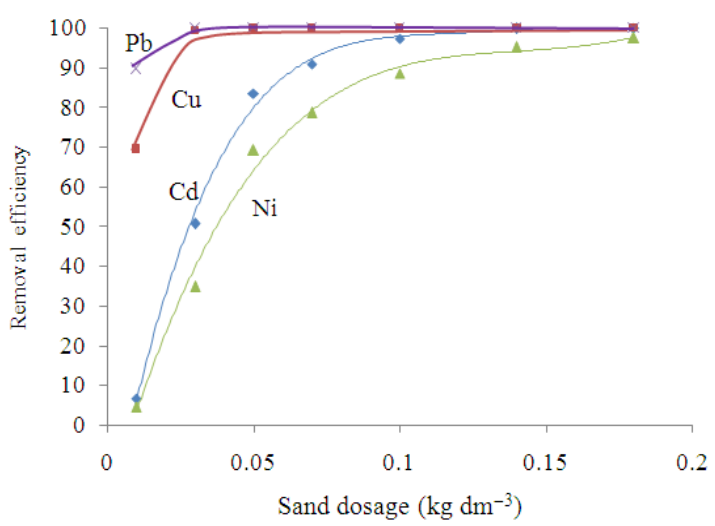

(b)

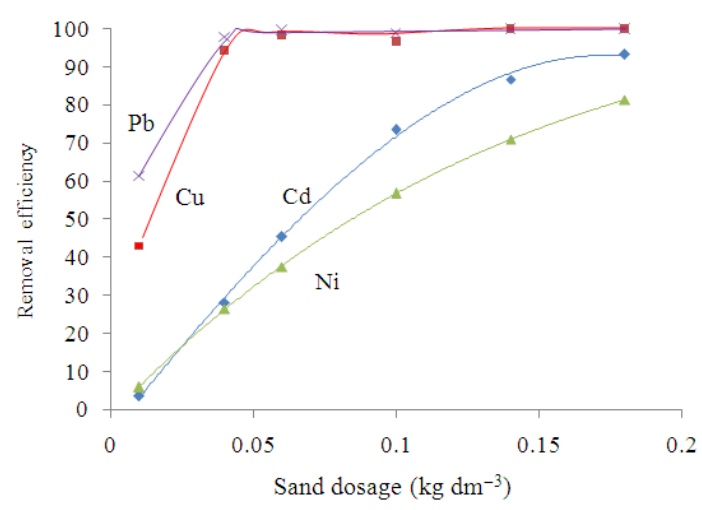

(c)

Fig. 1: Effect of sand dosage on heavy metal removal efficiency. (a) White sand; (b) yellow sand; (c) red sand. Contact time: $2 \mathrm{~h}, \mathrm{~T}=25.0^{\circ} \mathrm{C}$ 


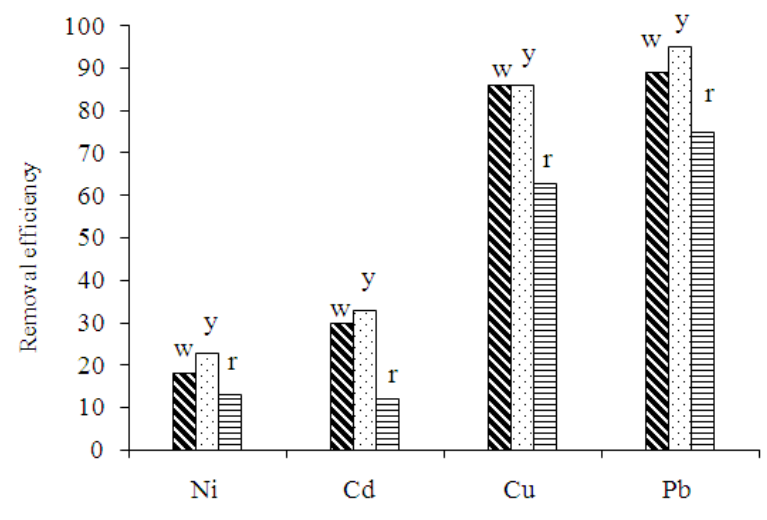

Fig. 2: Effect of sand type on heavy metal removal efficiency from a mixture containing $20.0 \mathrm{ppm}$ each of $\mathrm{Cd}(\mathrm{II}), \mathrm{Cu}(\mathrm{II}), \mathrm{Pb}(\mathrm{II})$ and $\mathrm{Ni}(\mathrm{II})$. Sand dosage $=0.020 \mathrm{~kg} \mathrm{dm}^{-3}$. Contact time $=2 \mathrm{~h}$, $\mathrm{T}=25.0^{\circ} \mathrm{C}$

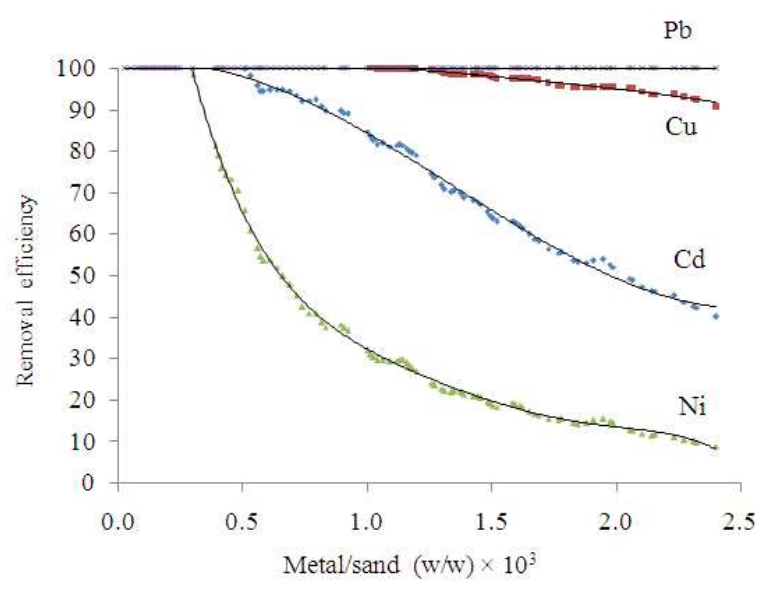

Fig. 3: Dependence of heavy metal removal efficiency on metal/sand ratio. $\mathrm{T}=25.0^{\circ} \mathrm{C}$

Figure 1 shows that the efficiency follows the order yellow>white>red for all four ions. This effect is further illustrated in Fig. 2, which summarizes data for $0.020 \mathrm{~kg} \mathrm{dm}^{-3}$ sand dosages. Figure 2 also shows that such a low sand dosage could be used to separate Cd(II) and $\mathrm{Ni}$ (II) ions from a solution containing the four ions. For the same sand type, removal efficiency follows the order $\mathrm{Pb}(\mathrm{II})>\mathrm{Cu}(\mathrm{II})>\mathrm{Cd}(\mathrm{II})>\mathrm{Ni}(\mathrm{II})$.

Sand column filtration: Under industrial conditions, it is practical to use columns to treat wastewater. The height of the sand column and the rate of flow of effluent could be controlled so as to achieve optimal efficiency. Figure 3 shows the dependence of removal efficiency on the mass ratio of heavy metal ion to that of yellow sand. For ratios lower than $3.0 \times 10^{-4}$, removal of all four ions was complete. As the ratio increases, $\mathrm{Ni}(\mathrm{II})$ begins to elute, followed by $\mathrm{Cd}(\mathrm{II})$. Figure 3 also shows that $\mathrm{Cu}$ (II) begins to elute at a significantly higher ratio, ca. $1.5 \times 10^{-3}$, whereas $\mathrm{Pb}$ (II) is completely removed in the region of detailed investigation. A separate experiment using a short column showed that $\mathrm{Pb}$ (II) is retained up to a mass ratio of $4.0 \times 10^{-2}$.

\section{DISCUSSION}

Removal of $\mathrm{Pb}(\mathrm{II})>\mathrm{Cu}(\mathrm{II})>\mathrm{Cd}$ (II) $>\mathrm{Ni}$ (II) via equilibration with sand and via sand filtration can be achieved with high efficiency. Equilibration at low sand dosages has shown that it would be possible to separate $\mathrm{Pb}$ (II) and $\mathrm{Cu}$ (II) from a mixture that also contains $\mathrm{Ni}$ (II) and $\mathrm{Cd}(\mathrm{II})$. The sand column results agree with those from batch equilibration, both demonstrating that it would be feasible to separate $\mathrm{Ni}$ (II) and $\mathrm{Cd}$ (II) from a mixture containing the four heavy metal ions. At a mass ratio of $2.0 \times 10^{-3}$, for example, $\mathrm{Pb}$ (II) is completely retained and $\mathrm{Cu}(\mathrm{II})$ is only ca. $5 \%$ eluted. By contrast $\mathrm{Cd}(\mathrm{II})$ and $\mathrm{Ni}(\mathrm{II})$ are ca. 50 and $88 \%$ eluted. Future research will be extended to other heavy metal ions, using sand as well as other low cost adsorbents and will involve studies on recovery of adsorbed species.

\section{CONCLUSION}

Equilibration on sand and sand filtration are most efficient for the removal $\mathrm{Pb}$ (II) and $\mathrm{Cu}(\mathrm{II})$. Sand filtration can be effectively utilized to separate $\mathrm{Pb}$ (II) and $\mathrm{Cu}(\mathrm{II})$ from a mixture containing all four ions.

\section{ACKNOWLEDGEMENT}

The authors wish to thank the American University of Sharjah for supporting this research.

\section{REFERENCES}

Aslam, M.M., I. Hassan and M. Malik, 2004. Sand as adsorbent of zinc from industrial effluents. Elect. J. Agric. Food Chem., 3: 792-798. http://ejeafche.uvigo.es/index.php?option=com_do cman\&task=cat_view\&gid=52\&Itemid=33.

Awan, M., I. Qazi and I. Khalid, 2003. Removal of heavy metals through adsorption using sand. J. Environ. Sci., 15: 413-416. PMID: 12938995

Babel, S. and T.A. Kumiawan, 2004. Chromium removal from electroplating wastewater using chemically treated zeolite. Proceedings of the 9th World Filtration Congress, Apr. 2004, AFS, New Orleans, USA., pp: 1-14. 
Baig, M.A., B. Mehmoud and A. Martin, 2003. Removal of chromium from industrial effluents by sand filtration. Elect. J. Agric. Food Chem., 2: 374-379.

http://ejeafche.uvigo.es/index.php?option=com_do cman\&task $=$ doc

Balkaya N., 2002. Variation of $\mathrm{pH}$, conductivity and potential values of chromium (VI) removal by wool. Environ. Technol., 23: 11-16. DOI: 10.1080/09593330309385530

Dakiky, M., M. Khamis, A. Manasra and M. Mer'eb, 2002. Selective adsorption of chromium (VI) in industrial wastewater using low-cost abundantly available adsorbents. Adv. Environ. Res., 6: 533-540. DOI: 10.1016/S1093-1091(01)0079-X
Khamis, M., F. Jumean and N. Abdo, 2009. Speciation and removal of chromium from aqueous solution by white, yellow and red UAE sand. J. Hazard. Mater., 169 : 948-952. DOI: 10.1016/j.jhazmat.2009. 04.053

Meunier, N.N., J. Laroulandie, J.F. Blais and R.D. Tyagi, 2003. Cocoa shells for heavy metal removal from acidic solutions. Bioresour. Technol., 90: 255-263. DOI: 10.1016/S0960-8524 (03)00129-9

Muhammad, N., J. Parr, M.D. Smith and A. Wheatley, 1998. Adsorption of heavy metals in slow sand filters. Proceedings of the 24th WEDC Conference, Sanitation and Water for All, Jan. 1998, Loughborough University, Islamabad, Pakistan, pp: 346-349. 